\title{
TATA LETAK FURNITURE PADA INTERIOR CAFE : STUDI KASUS RUANG CAFE MACAN MARELAN MEDAN
}

\author{
Juli Atika ${ }^{1}$, Andriansyah Harahap ${ }^{2}$ \\ Program Studi Desain Interior, Universitas Potensi Utama \\ Juliatika4@gmail.com ${ }^{1}$, Andriansyahharahap07@gmail.com ${ }^{2}$
}

\begin{abstract}
ABSTRAK
Cafe macan marelan merupakan tempat hiburan untuk anak muda pada zaman sekarang, cafe ini sangat banyak dikunjungi oleh anak muda, dengan adanya perubahan tata letak cafe macan marelan membuat pengunjung semakin tertarik untuk mengunjungi cafe tersebut, dimana dalam membuat tata letak interior pada cafe ini membuat pengunjung semakin nyaman untuk berkunjung ke cafe macan marelan. Medan merupakan kota kedua terbesar setelah jakarta, sebagai kota medan dengan masyarakat perkantoran trend globalisasi yang membutuhkan adanya cafe di daerah kota medan dalam kehidupan sehari-hari. Lain dari pada itu, waktu menjadi semakin berharga dan kehidupan kota menjadi hiruk pikuk dan bersifat rutin. Sehubung dengan hal itu, manusia menjadi condong untuk mencari hal-hal yang bersifat praktis dalam memenuhi kebutuhannya terhadap pasar untuk hiburan masyarakat, dalam hal ini pembuatan cafe sangat bermanfaat bagi masyarakat yang ada khususnya di marelan city maka dengan adanya perubahan dari tata letak cafe tersebut menjadi kenyamanan bagi para pengunjung cafe serta dapat meningkatkan jumlah pengunjung cafe Macan tersebut.
\end{abstract}

Kata Kunci: furniture, Marelan City, Cafe Macan Marelan.

\begin{abstract}
Macan marelan cafe is a place of entertainment for young people today, this cafe is very much visited by young people, with a change in the layout of Macan Marelan cafe making visitors more interested in visiting the cafe, where in making the interior layout of this cafe makes visitors more comfortable to visit the marelan macan cafe. Medan is the second largest city after Jakarta, as a Medan city with offices in the trend of globalization that requires a cafe in the area of Medan in everyday life. Other than that, time becomes more valuable and city life becomes frenzied and routine. In connection with this, humans are inclined to look for things that are practical in meeting their needs of the market for public entertainment, in this case the making of cafes is very beneficial for the community, especially in Marelan City, with a change in the layout of the cafe into convenience for cafe visitors and can increase the number of visitors to the Macan cafe.
\end{abstract}

Keywords: furniture, Marelan City, Marelan Macan Cafe.

\section{PENDAHULUAN}

Perkembangan kota Medan menjadi kota yang sangat pesat dalam perkembangan kota Medan yang modern memiliki karakteristik diantaranya adalah tingginya tingkat mobilitas kegiatan masyarakat dalam berbagai bidang. Kegiatan - kegiatan perdagangan / bisnis, perkantoran, industri, dan sebagainya; telah membawa masyarakat terjebak dalam rutinitas yang relatif sama dari waktu ke waktu dan cenderung monoton. Hal ini dapat menimbulkan 
kejenuhan yang berakibat menurunnya produktifitas. Mereka ingin melepaskan diri dari ketegangan - ketegangan dalam pekerjaan, kekhawatiran, dan konflik - konflik yang dihadapinya. Oleh karena itu mereka membutuhkan suatu tempat yang dapat memfasilitasi mereka untuk bersantai diantara waktu - waktu senggang yang dimilikinya. Salah satu contoh kegiatan untuk bersantai adalah merilekskan fikiran. Dengan merilekskan fikiran kita dapat menghilangkan kecemasan dan kegundahan. Selain itu dengan rileks kita dapat membuat hati semakin tenang. [1]

Marelan adalah sebuah kota kecil yang berada di kawasan Medan Sumatera Utara dimana kota marelan ini semakin berkembang pesat seperti selayaknya kota, sehingga kalangan anak muda zaman sekarang lebih cenderung ke kegiatan contohnya nongkrong, ngopi dan lain-lain. Pada kegiatan ini merancang sebuah tata letak cafe yang ada di maeelan Sumatera Utara, dimana pengunjung masih sangat antusias terhadap tata letak cafe tersebut, dengan adanya riset ini peneliti dapat membuat sebuah penelitian tentang tata letak cafe macan marelan tersebut, sehingga cafe tersebut terlihat begitu nyaman untuk para pengunjung yang berdatangan, dengan posisi awal yang di rubah hingga finish.

\section{STUDI LITERATUR}

Dalam penulisan makalah ini, penulis banyak melakukan studi literatur pada bukubuku, tesis, jurnal dan penelitian berkaitan tentang branding yang telah dilakukan oleh pengkarya sebelumnya. Data yang di dapat dari studi literatur ini digunakan sebagai acuan dalam membuat karya.

\section{Pengertian Coffee Shop}

Coffee Shop atau yang bisa disebut kedai kopi adalah suatu tempat (kedai) yang menyajikan olahan kopi espresso dan kudapan kecil. Seiring perkembangan zaman coffee shop ini menyediakan berbagai makan kecil dan makanan berat. (Kamus Besar Bahasa Indonesia, 1988). Coffee shop pertama di dunia yang tercatat diketahui muncul pada 1475. Coffee shop ini bernama Kiva Han dan berada di Kota Konstantinopel (sekarang Istanbul) Turki. Coffee shop ini diketahui menjadi coffee shop pertama yang buka dan melayani pengunjungnya dengan kopi khas Turki serta membuat para pengunjung semakin bertambah. Coffee shop pada zaman dahulu berbeda dengan coffee shop sekarang, yang tak hanya menyediakan menu minuman kopi tetapi juga makanan sebagai menu utamanya serta banyaknya ciri khas makanan yang ada di coffee shop. [2]

\section{Definisi Desain}

Saat ini terdapat sangat banyak definisi desain dari berbagai sudut pandang dan konteksnya dalam bentuk interior. Desain pun telah mengalami sejarah panjang dan mengalami perubahan pengertian dibanding pengertian sebelumnya yang menekankan unsur dekoratif dan kekriyaan dibanding fungsi Meninjau dari berbagai pengertian dalam pembuatan desain 2| Volume 3 Edisi 1, 2016 desain yang ada, desain merupakan upaya pemecahan masalah untuk memenuhi kebutuhan manusia. Untuk penjelasan yang lengkap, diperlukan masukan dari berbagai perspektif mengenai desain, berikut pengertian desain yang lain: [3]

Agus Sachari mengenai pengertian desain —Pada awal abad ke-20,_desain' mengandung pengertian sebagai suatu kreasi seniman untuk memenuhi kebutuhan tertentu dan cara tertentu pula (Walter Gopius, 1919). [3] 
Desain adalah Proses perancangan yang melibatkan kreatifitas manusia yang bertujuan membuat sebuah karya (to create something) sesuatu benda, sistem, dan sejenisnya dan memiliki manfaat bagi umat manusia. Desain merupakan manifestasi umat manusia dalam berkebudayaan yang menjadi ciri bagi peradabannya (Walter Gopius, 1919). Merupakan bidang keilmuan yang terintegrasi dengan seluruh induk bidang keilmuan yang didapat. Desain merupakan ilmu meramu/ merakit / memodifikasi sesuatu dari dasar-dasar kecabangan ilmu pengetahuan. Desain merupakan ilmu dasar untuk memecahkan masalah (problem solving). (Walter Gopius, 1919). [3]

\section{Desain Interior}

Profesi yang mengkaji dan mempelajari desain ruang dalam sebuah bangunan dengan bebagai pendekatan dan pertimbangan fungsi ruang, suasana, elemenestetis, pemilihan material, sosial budaya, gaya hidup, dan pertimbangan teknis penataan ruang serta membut kenyamanan gaya hidup. Dalam aspek keilmuan, desain interior mengkaji hal-hal yang berhubungan dengan prilaku sosial manusia dalam ruang, pencahayaan, elemen arsitektur, dan budaya pada umumnya. Proses perencanaan interior mencakup tahapantahapan berikut ini : [3]

- Pengumpulan Data

- Klasifikasi Dan Penyusunan Data

- Penyusunan Konsep Desain

Proses perancangan desain mencakup pendekatan desain berikut ini:

a. Pendekatan Fungsional

Pendekatan fungsional merupakan suatu pemecahan masalah dengan pertimbangan berupa kebutuhan kerangka hubungan antar bagian dalam suatu bangunan terhadap desain interior. Pada tahap ini, pola hubungan ruang dapat didasari secara teoritis, dengan menggunakan prinsip-prinsip bentuk pola linier, radial, cluster, memusat maupun grid. [3]

b. Pendekatan Psikologis

Pendekatan psikologis dalam desain interior dapat dilakukan dengan mempertimbangkan hirarki ruang berdasarkan tingkat kebutuhan privasi maupun berdasarkan orientasi. [3]

c. Pendekatan estetis

Dapat dilakukan dengan pertimbangan terhadap hal-hal dalam pembuatan desain interior sebagai berikut: proporsi, skala, keseimbangan, keserasian, kesatuan dan keragaman, ritme, penekanan/penegasan (D.K. Ching, Ilustrasi Desain Interior, 130). [3]

Menurut Cohen (1994, h.547) terdapat beberapa factor yang mempengaruhi desain interior suatu gedung yaitu ruang, warna, pencahayaan, sirkulasi udara dan tata suara. Berikut ini adalah uraiannya:

a.) Tata Ruang Menurut Ching (1996, h.71) kebutuhan luas ruang dibedakan dalam tiga jenis yaitu: 
(1) kebutuhan luas ruang terhadap tata letak caffe macan dan banyaknya orang yang dilayani,

(2) perlengkapan yang dibutuhkan pada ruang caffe tersebut, dan

(3) aktifitas yang dilakukan.

b.) Tata Warna Menurut Pamudji (2003, h.159) pemilihan warna dapat mempengaruhi kondisi seorang pemustaka, dimana warna pada dinding, lantai, atap dan perabot dapat menciptakan suasana hati dan kenyamanan seseorang yang berkungjung ke coffe macan tersebut.

c.) Pencahayaan Menurut Pamudji (2006, h.5) kegiatan di dalam ruang termasuk kegiatan bekerja, membutuhkan system pencahayaan yang efektif. Sumber penerangan dapat berasal dari cahaya buatan dan cahaya alami dalam sebuah desain interior.

d.) Sirkulasi Udara (Ventilasi) Ventilasi merupakan sistem pertukaran udara dalam ruang untuk menjaga kebersihan udara dan kelembaban ruang. Menururt Listiani dan Novalinda (2007, h.8) serta sebagai antisipasi kepengapan dapat menggunakan alat bantu AC (Air Conditioner), ventilasi dapat berupa jendela pada ruang caffe macan marelan.

e.) Tata Suara (Akustik) Akustik berhubungan dengan pendengaran seseorang. Perancangan tata suara bertujuan mengurangi ataupun menyingkirkan kebisingan pada suatu ruang serta membuat pengunjung lebih nyaman didalam caffe tersebut. [6]

\section{PEMBAHASAN}

Salah satu hal yang menyebabkan cafe macan marelan berkurangnya pengunjung adalah daya tarik furniture yang ada didalamnya sehingga cafe tersebut sepi dengan berkurangnya pengunjung, maka dari itu dengan adanya kreatifitas dari penulis untuk membuat tampilan cafe tampak lebih bagus dan untuk meningkatkan daya tarik pengunjung agar lebih banyak yang datang ke cafe macan marelan. 


\section{Desain}

\section{Manusia}

\section{Kreatif}

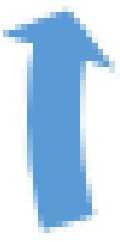

Karya

Kreatif
Proses

Kreatif

Gambar 1. Desain Keatif

1. Programming

Dalam melakukan pembuatan cafe macan ini memerlukan beberapa sofware untuk mendukung penyelesaian dalam pembuatan cafe macan ini, serta datadata baik fisik dan non-fisik yang didapat dikumpulkan dan disusun sesuai dengan kebutuhan perancangan yang akan dibuatdidalam sebuah caffe macan.

2. Konsep dan Skematik Desain

Konsep desain berupa jawaban atas dari permasalahan yang ada serta kebutuhan yang diinginkan dalam sebuah pembuatan desain cafe dan dibuat suatu batasan dalam perancangan desain cafe. Lalu dibuat sketsa desain yang diinginkan dari konsep yang ada.

3. Pengembangan desain

Pengembangan desain merupakan penyempurnaan desain cafe macan dari desain cafe macan sebelumnya yang kurang memenuhi batasan desain, agar dalam perancangan desain cafe macan memiliki konsep yang jelas dan benarbenar menjadi solusi desain.

4. Persyaratan Cafe

Cafe macan ini memiliki sebuah prinsip yang menyangkut persyaratan, yaitu persyaratan mengenai kenikmatan manusia yang dititik beratkan pada kebutuhan ruang gerak bagi individu adalah 1,4-1,7 m2. Desain mebel, dalam perancangan desain interior sebuah cafe macan marelan ini dapat mempengaruhi seorang pengunjung untuk berlama-lama duduk ataupun datang, makan lalu pergi. Standard dudukan kursi adalah $40 \times 40 \mathrm{~cm}$, tetapi 
sebaiknya dibuat $45 \times 45 \mathrm{~cm}$ agar pengunjung betah untuk berlama-lama di cafe macan tersebut.

5. Tata Ruang Cafe Macan Marelan

Tata ruang cafe hendaknya di desain sedemikian rupa sehingga peletakan meja dan kursi dapat diatur bervariasi dan dapat dirubah susunannya sewaktu-waktu disesuaikan dengan kebutuhan pelanggan yang mengiginkan tempat duduk secara berkelompok dalam satu meja. Tata ruang cafe sebaiknya memiliki fasilitas ruangan yang memadai agar dapat memberikan dukungan pekerjaan melakukan aktifitasnya, sehingga akan menghasilkan mutu produk yang berkualitas serta memberikan kenyamanan dan keselamatan kerja bagi para pekerja maupun kenyamanan bagi pelanggan cafe untuk menikmati produk cafe tersebut. Tata ruang cafe tentunya dirancang dan dibangun dengan mempertimbangkan siklus kegiatan oprasional, dimulai dari ruangan sebagai tempat melakukan kegiatan awal yakni penerimaan bahan mentah kemudian diproses sampai dengan penyajiannya.

6. Persyaratan Ruang Cafe Macan Marelan

a. Ruang Depan

Ruang Depan pada cafe macan yang dimaksud disini adalah ruanganruangan yang memiliki fungsi dan kegunaan yang diperuntukkan bagi pelanggan cafe maupun pengunjung cafe. Persyaratan untuk ruang depan yaitu :

- Penyekat antara cafe dengan dapur harus tahan api.

- Tersedia pintu keluar atau tangga darurat.

- Pintu keluar atau masuk pelanggan dengan pintu masuk atau keluar pegawai terpisah.

- Selalu terpasang alat deteksi kebakaran agar tidak terjadi suatu peristiwa yang mengakibatkan kerugian yang cukup besar.

- Sirkulasi pegawai dan pengunjung terjaga dengan baik.

- Mudah untuk dibersihkan dan dirawat oleh pekerja cafe macan marelan.

b. Ruang Belakang

Ruang belakang adalah ruang-ruang yang mempunyai fungsi dan kegunaan sebagai area penyimpanan untuk karyawan yang bekerja di cafe macan serta persiapan pengilahan produk makanan dan minuman yang digunakan untuk menampung aktifitas karyawan dan terlarang bagi pengunjung untuk masuk ke ruang belakang tersebut. Syarat ruang belakang yaitu :

- Penerangan cukup untuk melakukan aktifitas.

- Saluran pembuangan air memadai dan lancar.

- Terpasang alat penghisap atau saluran pembuangan asap dapur.

7. Karakteristik Pengguna Ruang Pengguna

Ketika pengunjung datang mereka tidak merasakan unsur atau tema dari cafe itu sendiri. Ikon macan dari cafe itu tidak melekat pada cafe serta tidak ada yang mencerminkan ikon cafe macan sehingga pengunjung belum merasa puas untuk berkunjung ke cafe macan tersebut. Kurangnya fasilitas seperti kursi yang menggambarkan karakteristik cafe dan tidak adanya penambahan seperti tanaman karena dengan diadakannya tanaman didalam ruangan cafe akan 
membaut kesan nature didalam ruangan agar sesuai dengan tema cafe itu sendiri, serta memberikan kenyamanan terhadap pengunjung cafe.

Dengan menambah ikon cafe dan furniture yang ditambahkan maka cafe tersebut akan terasa lebih nyaman dan sesuai dengan tema dari cafe itu sendiri serta tingkat masyarakat untuk berkunjung ke cafe ini semangkin bertambah jumlah nya dengan perubahan ikon cafe tersebut.

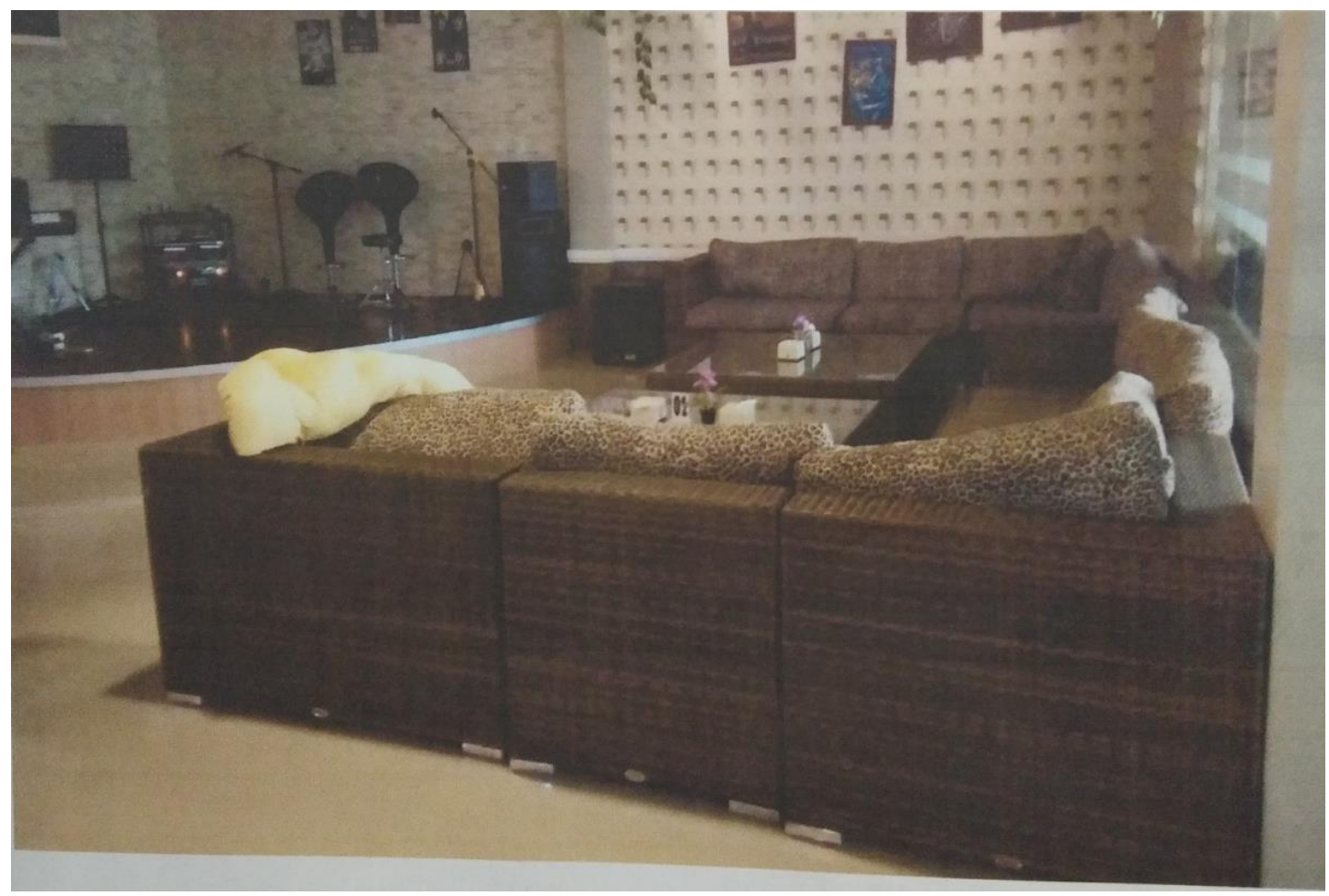

Gambar 2. Gambar Dasar Cafe Macan Marelan

Dalam gambar dasar cafe marelan medan terdapat beberapa desain interior sebelumnya terkait desain cafe marelan tersebut dan dalam desain cafe sebelumnya belum mendapatkan kenyamanan terhadap pengunjung yang ingin berkunjung ke cafe medan marelan dan ketidak nyamanan ini dirasakan oleh penulis sendiri serta penulis membuat salah satu problem tata letak pada cafe medan marelan tersebut.

Terdapat beberapa desain yang sudah di desain berdasarkan desain sebelumnya dan terdapat tambahan tata letak dari desain interior cafe macan marelan dalam desain tersebut terdapat kursi untuk tamu yang ingin menikmani menu makanan yang ada di cafe marelan dan interior tersebut terdapat di dalam gambar 2 pada gambar remake cafe macan marelan. 


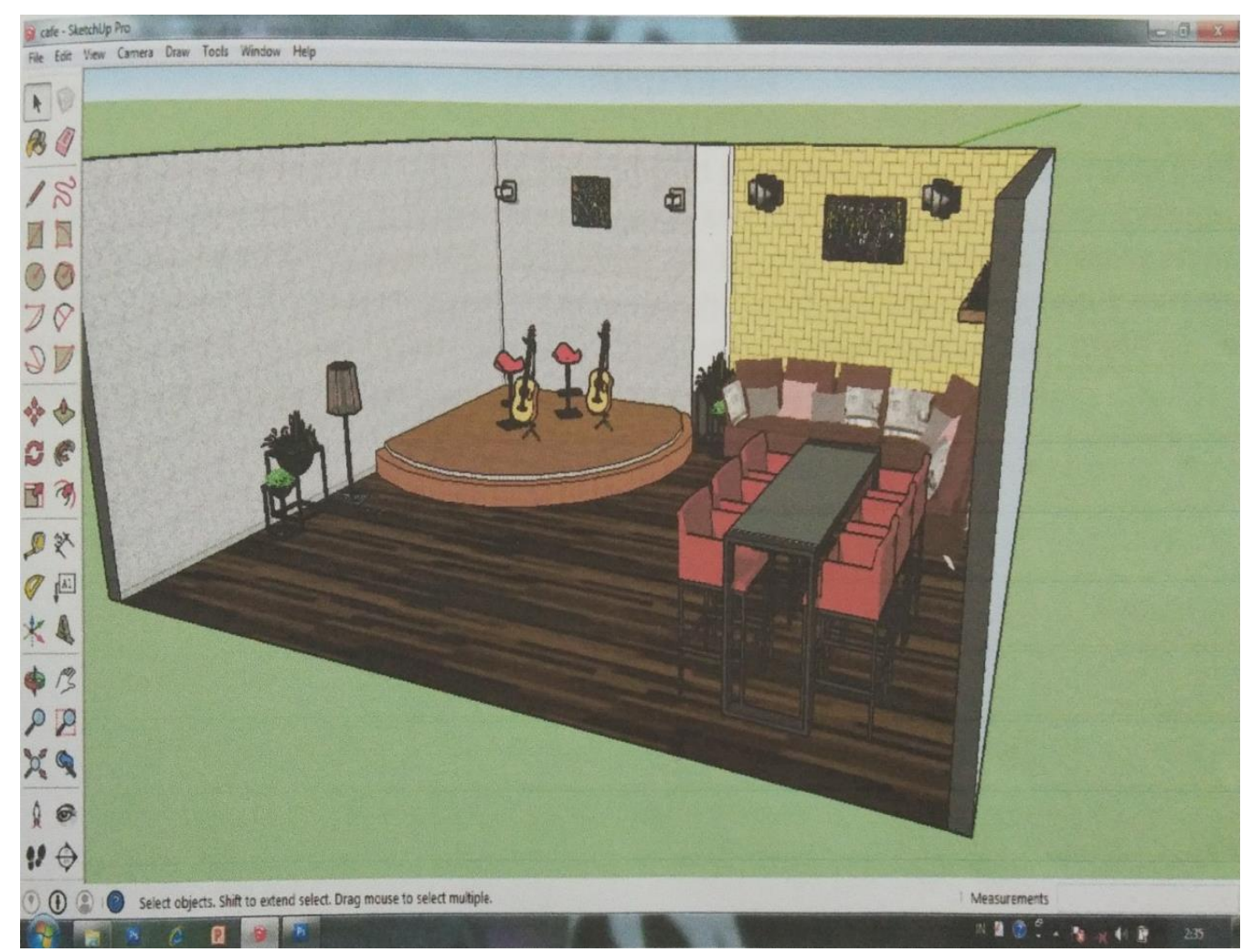

\section{Gambar 3. Gambar Remake Cafe Macan Marelan}

Dalam remake cafe macan marelan terdapat beberapa fasilitas untuk pengunjung serta fasilitas tersebut agar membuat pengunjung semakin ramai karena bertambahnya fasilitas yang ada di cafe macan marelan medan. Dalam hal ini pengunjung seiring bergantinya waktu cafe tersebut diminati para pengunjung termasuk kalangan para remaja yang ingin bersantai di cafe macan dan gambar cafe macan ini di perlihatkan dari arah atas untuk memperlihatkan suasana cafe macan sehingga cafe tersebut terlihat lebih menarik.

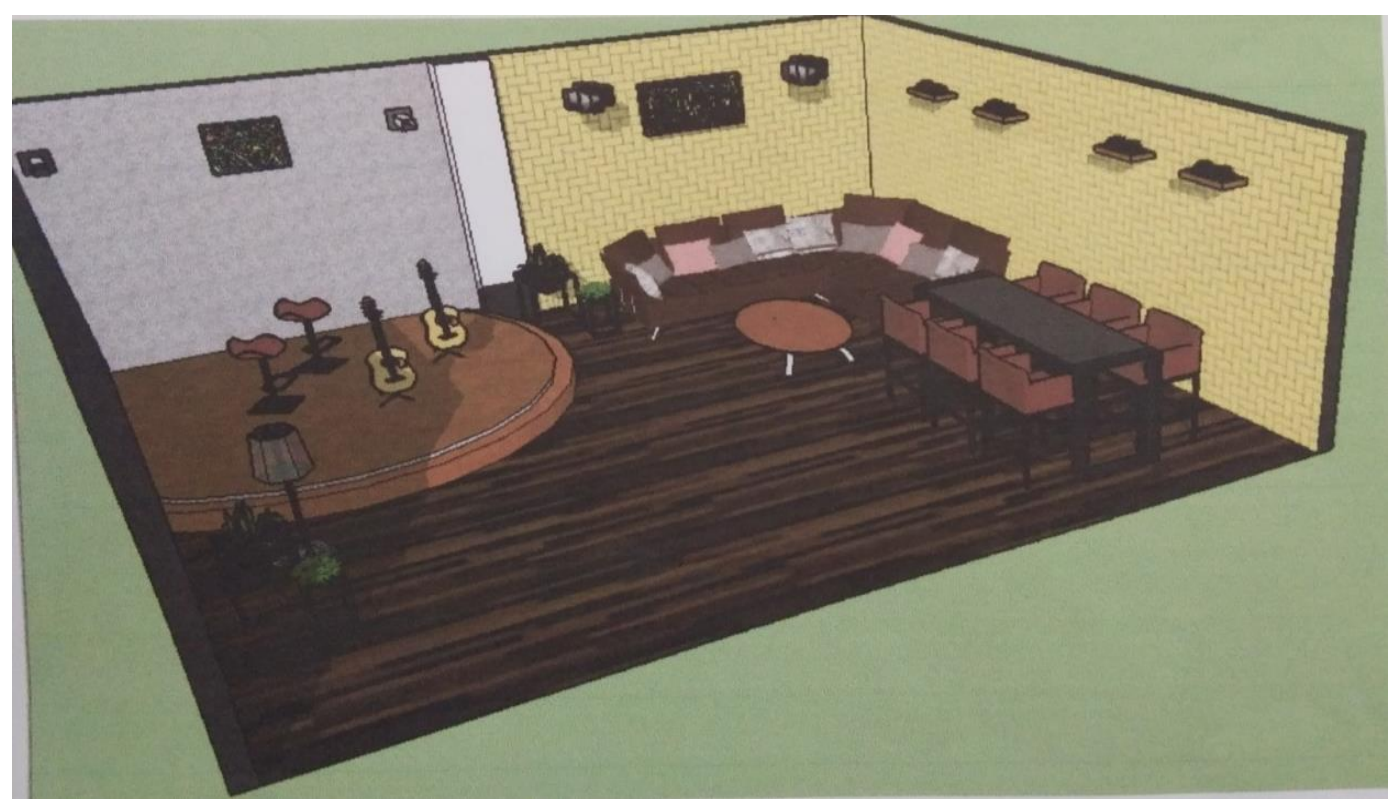

Gambar 4. Cafe Macan Marelan 
Pada gambar 3 terdapat cafe macan marelan tampak atas dan pada tampilan ini cafe macan marelan lebih kelihatan interior full serta lebih terlihat mewah dibandingkan pada cafe macan marelan sebelumnya dan terdapat beberapa alat musik serta perlengkapannya dan kursi untuk menghidangkan pesanan pengunjung serta terdapat sofa untuk kenyamanan pengunjung yang ingin bersantai dan dibagian dinding terdapat beberapa furniture dari cafe macan marelan tersebut.

Desain interior merupakan salah satu hal yang cukup penting dalam rancangan su atu bangunan, khususnya dalam hal ini adalah pembangunan perpustakaan. Perpustakaan yang baik dalam perencanaan gedung dan ruang per- pustakaannya perlu memperhatikan fungsi tiap ruang, unsur-unsur keharmonisan dan keindahan, baik dari segi interior dan eksterior. Ruang per- pustakaan akan nyaman bagi pemakai apabila ditata dengan memperhatikan fungsi, keindahan, dan keharmonisan ruang. Dengan demikian pengaruh desain interior terhadap kenyamanan membaca akan memberikan manfaat apabila desain interior perpustakaan dapat disesuaikan dengan kebutuhan dan keinginan pemustaka.

Dalam hal ini perubahan yang terjadi terhadap cafe macam marelan sangat banyak sehingga para pengunjung ingin sekali berkunjung ke cafe macan dengan adanya desain yang baru di cafe tersebut membuat orang tertarik akan keindahan interior dari cafe macan tersebut.

Penelitian ini menggunakan metode penelitian kualitatif dengan tipe penelitian deskriptif. Penelitian deskriptif ini dipilih agar dapat diketahui secara detail mengenai persepsi visual yang muncul terhadap elemen interior pada cafe macan marelan tersebut dengan data yang didapat dari sumber yang ada dilapangan, kemudian dianalisis dengan studi pustaka yang berkaitan dengan British Interior Design dalam sebuah cafe macan marelan. Pengumpulan data dilakukan dengan studi literatur, wawancara dan observasi objek secara langsung.

Studi literatur dilakukan dengan cara mencari dan mencatat informasi yang memuat teori yang berhubungan dengan objek penelitian sehingga diperoleh data yang mendukung pemecahan masalah dalam penelitian dalam bidang desain interior serta mencari sebuah aspek terhadap ruang cafe macan marelan. Pengumpulan data dilakukan dengan teknik observasi yang didasarkan atas pengalaman langsung yang memungkinkan melihat dan mengamati sendiri, kemudian mencatat sesuai dengan apa yang dilihat dan dirasakan oleh pengunjung cafe macan tersebut.

Wawancara dan dokumentasi yang di lakukan oleh peneliti juga merupakan teknik dari pengumpulan data yang akurat. Wawancara dilakukan pada pemilik Cafe Macan dan dokumentasi dilakukan dilokasi penelitian. Pengumpulan data dilakukan dengan tujuan agar peneliti mengetahui terhadap berbagai aspek persepsi visual pengunjung terhadap elemen interior ditinjau dari sisi pencahayaan, warna, ukuran dan bentuknya pada Cafe Macan di Medan Marelan.

\section{KESIMPULAN}

Cafe merupakan tempat berkumpulnya anak-anak kalangan remaja dimana cafe tersebut bisa merupakan trend bagi anak muda di zaman sekarang baik itu pria maupun wanita dan Kuliner adalah suatu bagian hidup yang di rasakan oleh masyarakat serta erat kaitannya dengan komunikasi makanan ataupun juga sebuah gaya hidup yang tidak dipisahkan dari kehidupan sehari-hari. Oleh karena itu kuliner sangat penting dalam kehidupan serta kuliner dapat menimbulkan rasa keingintahuan bagi masyarakat yang ada. Medan merupakan kota kedua terbesar setelah jakarta, sebagai kota metropolitan dengan 
masyarakat perkantoran trend globalisasi yang membutuhkan adanya cafe dalam kehidupan sehari-hari.

Lain dari pada itu, waktu menjadi semakin berharga dan kehidupan kota menjadi hiruk pikuk dan bersifat rutin untuk menikmatai sebuah kuliner. Sehubung dengan hal itu, masyarakat luas menjadi condong untuk mencari hal-hal yang bersifat praktis dalam bidang kuliner untuk memenuhi kebutuhannya, dalam hal ini pembuatan cafe sangat bermanfaat bagi masyarakat yang ada khususnya di marelan city maka dengan adanya perubahan dari tata letak cafe tersebut menjadi kenyamanan bagi para pengunjung cafe serta dapat meningkatkan jumlah pengunjung cafe Macan tersebut.

Adapun pembuatan cafe ini sebelumnya belum mendapatkan hasil yang memuaskan bagi para pengunjung sehingga peneliti membuat tata letak untuk cafe macan marelan tersebut agar tata letak tersebut memerikan kenyamanan bagi para pengunjung serta bagi para pencinta kuliner.

\section{DAFTAR PUSTAKA}

[1] Desain Interior Kristen Petra. 2015. JURNAL INTRA Vol. 3, No. 2, (2015) 286-293

[2] Desain Interior Kristen Petra. 2017. Jurnal Intra Vol 6, No.1, (2017) 15-25

[3] Desain dan Seni Kreatif Universitas Mercu Buana Jakarta. 2016. Jurnal NARADA Volume 3 Edisi 1, (2016)

[4] Desain Interior Kristen Petra. 2014. JURNAL INTRA Vol 2, No.2, (2014) 107-117

[5] Desain Interior Kristen Petra. 2015. JURNAL INTRA Vol 3, No. 2, (2015) 143-150

[6] Administrasi Publik Universitas Briwijaya. Jurnal Administrasi Publik (JAP), Vol. 3, No. 11, 1868-1873 